\title{
Healthy Living: Beating Barriers to Physical Activity ${ }^{1}$
}

Jennifer Hillan ${ }^{2}$

Being active can help you function better and stay independent. It also ENAFS can reduce your risk for getting some diseases, such as diabetes, and help you manage health problems you already have. If you're not active, what's stopping you from getting started? Read on to learn how to overcome some of these barriers!

\section{Common Barriers and Solutions}

I don't have time to exercise for thirty

minutes every day.

Do as much as you can. Every bit of activity adds up! Start with ten minutes a day and gradually add more time. You don't have to be active for thirty minutes all at once.

It's not safe to walk in my neighborhood. Find an indoor activity, such as an exercise class at a community center or mall walking.

I don't like to exercise in a group.

Choose something you can do on your own, such as walking outside or following an exercise program on TV or video.

Physical activity is boring.

Find an activity you like to do. Ask a friend to be active with you. Vary your routine.

Walking hurts my knees, and I have bad balance.

Try chair dancing or swimming.
It's too hot outside.

Walk inside a shopping center or grocery store or use an exercise video at home.

I don't have the right clothes.

Wear anything that's comfortable! Be sure your shoes fit well and your socks don't irritate your skin.

I'm afraid I'll make my condition worse. Talk with your health care provider to learn what is safe for you.

I can't afford to join a fitness center or buy expensive equipment. All you need is a good pair of walking shoes!

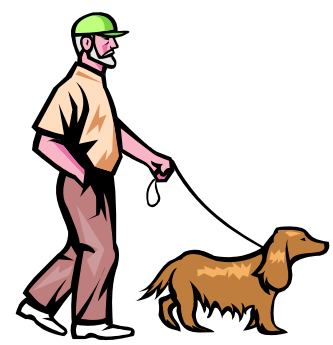

I'm afraid I'll get low blood glucose. If you're taking medication that can cause low blood glucose, talk to your health care provider about how to exercise safely.

1. La versión en español de este documento es Vida Saludable: Derrumbando Barreras en Contra de la Actividad Física (FCS8818-Span). Adapted from Overcoming Barriers, American Diabetes Association. This document is FCS8818, one in a series of the Department of Family, Youth and Community Sciences, Florida Cooperative Extension Service, IFAS, University of Florida, Gainesville, FL 32611. First published: December 2006. Please visit the EDIS Web site at http://edis.ifas.ufl.edu.

2. Jennifer Hillan, MSH, RD, LD/N, ENAFS nutrition educator, Department of Family, Youth and Community Sciences, Florida Cooperative Extension Service, Institute of Food and Agricultural Sciences, University of Florida, Gainesville, FL 32611. 